\title{
Reinvestigation of the $\mathrm{DyCl}_{3}-\mathrm{LiCl}$ binary system phase diagram
}

\author{
A. Dańczak ${ }^{1} \cdot$ L. Rycerz ${ }^{1}$
}

Received: 8 November 2015/ Accepted: 13 May 2016/Published online: 26 May 2016

(C) The Author(s) 2016. This article is published with open access at Springerlink.com

\begin{abstract}
The phase equilibria in the $\mathrm{DyCl}_{3}-\mathrm{LiCl}$ binary system were established on the basis of differential scanning calorimetry (DSC) measurements. One compound, namely $\mathrm{Li}_{3} \mathrm{DyCl}_{6}$, is formed in this system. It melts congruently at $768 \mathrm{~K}$ with enthalpy of $51.6 \mathrm{~kJ} \mathrm{~mol}^{-1}$. DSC curves for eutectic composition and for compositions close to eutectic (on the left and right side of eutectic) are identical. Small effect related to the liquidus is shadowed by a big effect related to eutectic, and only one thermal effect is visible. This is the reason that eutectic composition can not be determined directly. The only possibility to determine it precisely is a creation of Tammann diagram. Two eutectics, namely $\mathrm{LiCl}-\mathrm{Li}_{3} \mathrm{DyCl}_{6}$ and $\mathrm{Li}_{3} \mathrm{DyCl}_{6}-$ $\mathrm{DyCl}_{3}$, located at $\mathrm{DyCl}_{3}$ mol fractions $x=0.206$ $(T=746 \mathrm{~K})$ and $x=0.542(T=674 \mathrm{~K})$ were found from Tammann's plots, which predict, through application of the lever rule, the variation of the enthalpy associated with eutectic melting as a function of composition.
\end{abstract}

Keywords DSC - Phase diagram · Dysprosium chloride · Lithium chloride $\cdot$ Tammann diagram

A. Dańczak

anna.danczak@pwr.edu.pl

1 Division of Analytical Chemistry and Analytical Metallurgy, Faculty of Chemistry, Wrocław University of Technology, Wybrzeże Wyspiańskiego 27, 50-370 Wrocław, Poland

\section{Introduction}

Rare-earth halides are used in a number of applications such as reprocessing of nuclear wastes, recycling of spent nuclear fuel [1], doses in high-intensity discharge lamps, lasers and new highly efficient light sources with energysaving features [2,3]. Technological application of lanthanides halides requires knowledge of their basic thermodynamic properties. These properties are indispensable, e.g., for calculation of the chemical composition in the lamps to enable understanding and hence prediction of tungsten corrosion, silica corrosion and spectra output. The basic thermodynamic properties are also needed for predicting the behavior of doses by modeling of multi-component metal halide systems [4]. However, the available in the literature thermodynamic data on lanthanide halides are very often scarce or contradictory.

Pioneering works devoted to the phase diagrams of lanthanide chloride-alkali metal chloride systems were performed in the sixties of the twentieth century mainly at the Lomonosov University in Moscow [5]. The extensive summaries about chloride systems up to 1977 can be found in the handbook [6] and in the monograph by Prosypajko and Alekseeva [7]. These investigations were accomplished by visual polythermal method. This technique is not a very accurate method and can give quite good results for liquidus lines and thus for existence of congruently melting compounds; however, data on the composition of incongruently melting compounds can be doubtful. Furthermore, solid-state reactions with small reaction enthalpies were often overlooked. As a consequence, all the investigated systems with $\mathrm{NaCl}$ were incomplete [5]. Indeed, such a situation could be observed in the case of dysprosium chloride-alkali metal chloride systems. The pioneering work by Korshunov and Drobot [8] 
demonstrated the existence of $\mathrm{Na}_{3} \mathrm{DyCl}_{6}$ and $\mathrm{NaDy}_{3} \mathrm{Cl}_{10}$, incongruently melting compounds in the $\mathrm{DyCl}_{3}-\mathrm{NaCl}$ system, whereas the later work of by Seifert et al. [9] performed by DTA technique showed the existence of three incongruently melting compounds in this system with the following stoichiometry: $\mathrm{Na}_{3} \mathrm{DyCl}_{6}, \mathrm{NaDyCl}_{4}$ and $\mathrm{NaDy}_{2} \mathrm{Cl}_{7}$. Korshunov and Drobot [8] found two congruently melting compounds, namely $\mathrm{K}_{3} \mathrm{DyCl}_{6}$ and $\mathrm{KDy}_{3} \mathrm{Cl}_{10}$, in the $\mathrm{DyCl}_{3}-\mathrm{KCl}$ system by visual polythermal method, but Blachnik and Selle [10] demonstrated the existence of three compounds on the basis of DTA measurements. Two of them, namely $\mathrm{K}_{3} \mathrm{DyCl}_{6}$ and $\mathrm{KDy}_{2} \mathrm{Cl}_{7}$, melt congruently, and $\mathrm{K}_{2} \mathrm{DyCl}_{5}$ melts incongruently. The above examples confirm the statement about serious errors and lack of precision of existing phase diagrams of lanthanide chloride-alkali metal chloride binary systems that have been published in the literature. These differences were the cause of systematic reinvestigation of all lanthanide chloride-alkali metal chloride phase diagrams (alkali metal $=\mathrm{Na}, \mathrm{K}, \mathrm{Rb}, \mathrm{Cs}$ ) that were undertaken by the Seifert's group from the University of Kassel [5, 11]. Among others, the phase diagrams of the $\mathrm{DyCl}_{3}-\mathrm{MCl}(\mathrm{M}=\mathrm{Na}, \mathrm{K}$, $\mathrm{Rb}, \mathrm{Cs}$ ) systems were constructed on the basis of thermal analysis, electrochemical and structural measurements [12]. They confirmed the results obtained by Blachnik and Selle [10] concerning $\mathrm{DyCl}_{3}-\mathrm{KCl}$ system. Indeed, three compounds were identified in this system. Two of them melt congruently $\left(\mathrm{K}_{3} \mathrm{DyCl}_{6}\right.$ and $\left.\mathrm{KDy}_{2} \mathrm{Cl}_{7}\right)$, and the third melts incongruently. As it was stated above, systematic investigations or reinvestigations were performed on the systems of lanthanide chlorides with alkali metal chlorides, with exception of the systems with lithium chloride. Fragmentary information concerning the phase equilibria in the systems of lanthanide chlorides with lithium chloride comes mainly from Chinese journals [13-16]. According to them, the systems with lithium chloride are simple eutectic systems $\left(\mathrm{LaCl}_{3}, \mathrm{CeCl}_{3}, \mathrm{PrCl}_{3}\right.$ and $\left.\mathrm{NdCl}_{3}\right)$, systems with $\mathrm{LiLn}_{2} \mathrm{Cl}_{7}$ compounds that decompose to a solid-state phase $(\mathrm{Ln}=\mathrm{Sm}, \mathrm{Tb})$ or systems with $\mathrm{Li}_{3} \mathrm{LnCl}_{6}$ compounds that melt incongruently $(\mathrm{Ln}=\mathrm{Dy}, \mathrm{Ho}, \mathrm{Er}, \mathrm{Yb})$. According to the literature data [16], the $\mathrm{DyCl}_{3}-\mathrm{LiCl}$ system is characterized by the existence of $\mathrm{Li}_{3} \mathrm{DyCl}_{6}$ compound that undergoes a solid-solid phase transition at $743 \mathrm{~K}$ and melts incongruently at $748 \mathrm{~K}$. It should be pointed out that the authors did not inform about a solid-solid phase transition of $\mathrm{DyCl}_{3}$, which is well known from the literature [17]. So, we decided to reinvestigate this system by DSC.

The present work is a part of a multi-instrumental, international program focused on lanthanide halides and their systems with alkali metal halides. The main purpose of this program is to contribute new experimental data concerning unknown systems and verification of the existing data. In the present work, differential scanning calorimetry was used to study thermodynamic properties of $\mathrm{DyCl}_{3}$ and the phase equilibrium in $\mathrm{DyCl}_{3}-\mathrm{LiCl}$ binary system.

\section{Experimental}

\section{Chemicals and samples preparation}

Dysprosium(III) chloride was synthesized from dysprosium oxide ( $99.9 \%$, Sigma-Aldrich). The first step of this synthesis was dissolution of $\mathrm{Dy}_{2} \mathrm{O}_{3}$ in hot concentrated $\mathrm{HCl}$. The obtained solution was evaporated, and $\mathrm{DyCl}_{3} \cdot 6 \mathrm{H}_{2} \mathrm{O}$ was crystallized. Then ammonium chloride was added, and the obtained mixture of hydrated $\mathrm{DyCl}_{3}$ and $\mathrm{NH}_{4} \mathrm{Cl}$ was slowly heated up to $1070 \mathrm{~K}$ under vacuum in order to remove water and to sublimat unreacted $\mathrm{NH}_{4} \mathrm{Cl}$. Finally, the crude $\mathrm{DyCl}_{3}$ was purified by distillation under reduced pressure $(\sim 0.1 \mathrm{~Pa})$. The obtained in such a way $\mathrm{DyCl}_{3}$ was of high grade (min. $99.9 \%$ ). Chemical analysis was performed by complexometric (dysprosium) and argentometric (chloride) methods. The results were as follows: Dy: $60.40 \pm 0.12 \%$ (60.44\% theoretical); $\mathrm{Cl}: 39.60 \pm 0.13 \%$ (39.56\% theoretical). After the synthesis, $\mathrm{DyCl}_{3}$ was ground in a glove box and stored in ampoules sealed under dry argon atmosphere.

The purity of anhydrous lithium chloride was $99.9 \%$ (Alfa Aesar).

The appropriate amounts of $\mathrm{DyCl}_{3}$ and $\mathrm{LiCl}$ were melted in vacuum-sealed quartz ampoules in an electric furnace. The melts were homogenized by shaking and solidified. Theses samples were ground in an agate mortar in a glove box. The prepared in this way homogenous mixtures used in measurements focused on phase diagram determination.

\section{Measurements}

A Setaram Labsys Evo differential scanning calorimeter (DSC) was used to investigate the phase equilibria in the $\mathrm{DyCl}_{3}-\mathrm{LiCl}$ system. Experimental samples (100-400 mg) were kept in vacuum-sealed quartz ampoules (about $6 \mathrm{~mm}$ diameter, $15 \mathrm{~mm}$ length). The DSC experiments on samples with 28 compositions were conducted at heating and cooling rates ranging from 1 to $10 \mathrm{~K} \mathrm{~min}^{-1}$.

\section{Results and discussion}

\section{Phase diagram}

DSC investigations performed on 28 samples with different compositions yielded both the temperature and the fusion enthalpy of the concerned mixtures. Due to the 
supercooling effect observed during cooling runs, all the values of temperature and enthalpy given in this work were determined from the heating curves.

It was established that $\mathrm{DyCl}_{3}$ undergoes a solid-solid phase transition at $606 \mathrm{~K}$ and melts at $914 \mathrm{~K}$. These findings are in a good agreement with the literature data [18] that reports $611 \mathrm{~K}$ and $919 \mathrm{~K}$ for transition and fusion,
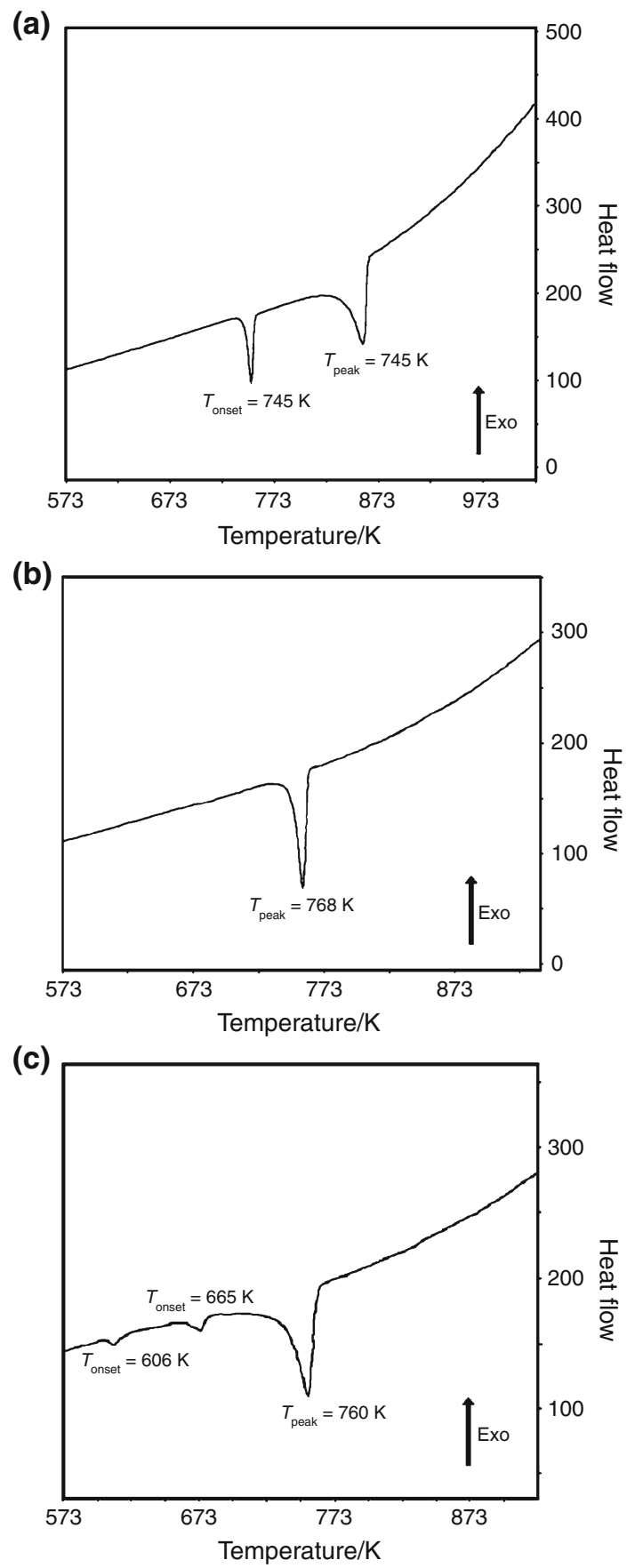

Fig. 1 DSC curves obtained for samples with mole fraction of $\mathrm{DyCl}_{3}$ $x=0.050(\mathbf{a}), 0.250(\mathbf{b}), 0.348(\mathbf{c})$ obtained with heating rate of $5 \mathrm{~K} \mathrm{~min}^{-1}$ respectively. Figure 1 shows the DSC curves obtained for the samples with the mole fraction of $\mathrm{DyCl}_{3}, x=0.050$ (a), 0.250 (b), 0.348 (c), obtained with heating rate of $5 \mathrm{~K} \mathrm{~min}^{-1}$.

In the composition range $0<x<0.250$, where $x$ is a mole fraction of $\mathrm{DyCl}_{3}$, two endothermic peaks were present in the all heating DSC curves (Fig. 1a). The effect at the highest temperature corresponds to the liquidus temperature. The second one at $746 \mathrm{~K}$ was observed up to $x=0.250$, then it disappeared, thus suggesting an existence of a compound with the stoichiometry $\mathrm{Li}_{3} \mathrm{DyCl}_{6}$. This thermal feature can be undoubtedly assigned to the $\mathrm{LiCl}-\mathrm{Li}_{3} \mathrm{DyCl}_{6}$ eutectic. Proper determination of a eutectic composition requires creation of the so-called Tammann diagram. This diagram is an important outcome from the theory of phase diagrams [19-21]. It predicts, through application of the lever rule, the variation of the enthalpy associated with a first-order transformation as a function of concentration. Regrettably, this plot is seldom used or merely overlooked, although it provides valuable information [20]. In order to illustrate its utility, the eutectic melting (Fig. 2) should be considered. For the eutectic mole fraction of component $\mathrm{B}, x_{\text {eut }}$, there is only one melting effect corresponding to an enthalpy $\Delta_{\text {eut }} H$. For other compositions, the enthalpy $\Delta H$ given off at the eutectic temperature is proportional to the mole fraction $x_{\text {eut }}^{*}$ of eutectic liquid formed

$\Delta H=x_{\text {eut }}^{*} \Delta_{\text {eut }} H$

Enthalpies should be expressed in joules per mole of sample. Thanks to the lever rule, $x_{\text {eut }}^{*}$ can be expressed through:

$$
\begin{array}{ll}
\text { for } x \leq x_{\text {eut }} & x_{\text {eut }}^{*}=(x-0) /\left(x_{\text {eut }}\right) \\
\text { for } x \geq x_{\text {eut }} & x_{\text {eut }}^{*}=(1-x) /\left(1-x_{\text {eut }}\right)
\end{array}
$$

in which $x$ is a mole fraction of component $\mathrm{B}$. Relations (1), (2) and (3) indicate that the variation of $\Delta H$ with mole fraction of component $\mathrm{B}$ must be linear and going from A

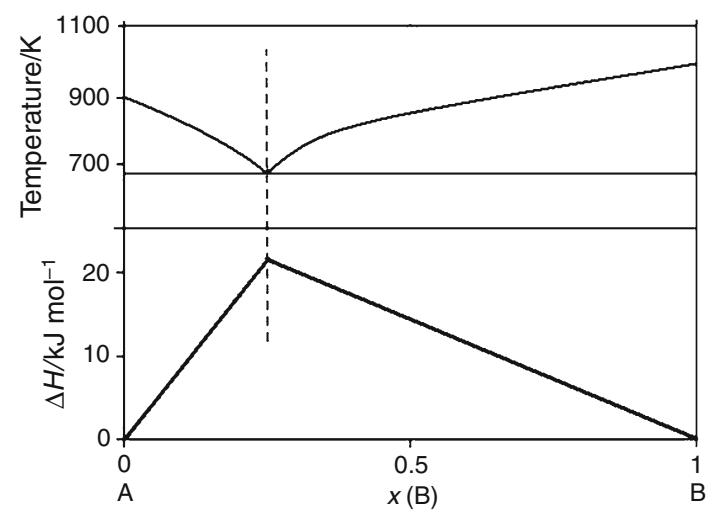

Fig. 2 Tammann plot of typical eutectic phase diagram 
to $\mathrm{B}, \Delta H$ must increase from zero at $x=0$ up to $\Delta_{\text {eut }} H$ at $x=x_{\text {eut }}$, and then decrease down to zero at $x=1$. Accordingly, $x_{\text {eut }}$ can be determined straightforwardly by means of Tammann's plot. The Tammann plot should start at wherever the left and the right endpoints of the eutectic line are. This means that the plot can give us information on both the eutectic composition and the solid solubilities at eutectic temperature. (The latter are typically the maximum solubilities).

The eutectic contribution to the enthalpy of fusion was determined and plotted against composition in Fig. 3. This Tammann diagram allows to accurately determine the eutectic composition from the intercept of the two linear parts (Fig. 3b), as $x=0.206 \pm 0.0086$. The mixture with eutectic composition melts with enthalpy, $\Delta_{\text {fus }} H_{\mathrm{m}}$, of about $13.24 \pm 1.55 \mathrm{~kJ} \mathrm{~mol}^{-1}$ at temperature $746 \mathrm{~K}$ (a mean value from the experimental values). During construction of the Tammann diagram, it was assumed that there was no solubility in the solid state. Thus, the straight lines intercept the composition axis at $x\left(\mathrm{DyCl}_{3}\right)=0.0$ and 0.250 .

Only one thermal effect at $768 \mathrm{~K}$ was observed on DSC curve for the sample with mole fraction $x\left(\mathrm{DyCl}_{3}\right)=0.250$ (Fig. 1b). It corresponds to congruent melting of $\mathrm{Li}_{3} \mathrm{DyCl}_{6}$ compound. The related to this effect molar enthalpy is equal to $51.6 \mathrm{~kJ} \mathrm{~mol}^{-1}$.

Three thermal effects were observed on the DSC curves for the samples with mole fraction $0.250<x\left(\mathrm{DyCl}_{3}\right)$ $<1.00$ (Fig. 1c). The thermal effect at $606 \mathrm{~K}$ corresponds to the solid-solid phase transition of $\mathrm{DyCl}_{3}$. The enthalpy values related to the effect at $606 \mathrm{~K}$ increase with the increasing mole fraction of $\mathrm{DyCl}_{3}$ (Fig. 3c). The second effect at $674 \mathrm{~K}$ (a mean value from experiments) corresponds to $\mathrm{Li}_{3} \mathrm{DyCl}_{6}-\mathrm{DyCl}_{3}$ eutectic. The eutectic composition $x\left(\mathrm{DyCl}_{3}\right)=0.542 \pm 0.0139$ was determined from

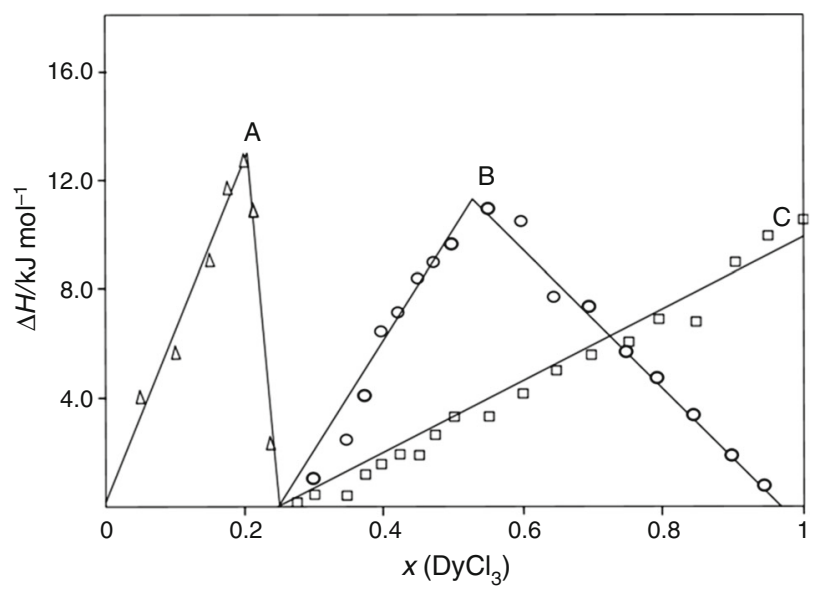

Fig. 3 Tammann plot of $\mathrm{DyCl}_{3}-\mathrm{LiCl}$ binary system: determination of $a$ (open triangle) $\mathrm{LiCl}-\mathrm{Li}_{3} \mathrm{DyCl}_{6} ; b$ (open circle) $\mathrm{Li}_{3} \mathrm{DyCl}_{6}-\mathrm{DyCl}_{3}$ eutectic composition; $c$ (open square) phase transition of $\mathrm{DyCl}_{3}$ the Tammann plot displayed in Fig. 3b. The mixture with eutectic composition melts with enthalpy, $\Delta_{\text {fus }} H_{\mathrm{m}}$, of about $11.03 \pm 0.49 \mathrm{~kJ} \mathrm{~mol}^{-1}$ at temperature $674 \mathrm{~K}$. The effect at the highest temperature corresponds to the liquidus temperature.

On the DSC curves, the overlapping of thermal effects related to the eutectic and liquidus was observed, especially for the samples with a mole fraction near to the composition of eutectic (Fig. 4a). Due to this overlapping, it was impossible to determine enthalpy related to the eutectic, which was necessary for Tammann diagrams construction. Thus, it was necessary to perform deconvolution of the overlapping peaks. This separation was made with CALISTO software included in the Labsys Evo differential scanning calorimeter system. The result of application of the peak separation tool is displayed in Fig. $3 b$. As a result of peaks separation enthalpy related to the eutectics could be determined and used subsequently in the described above Tammann diagrams construction.
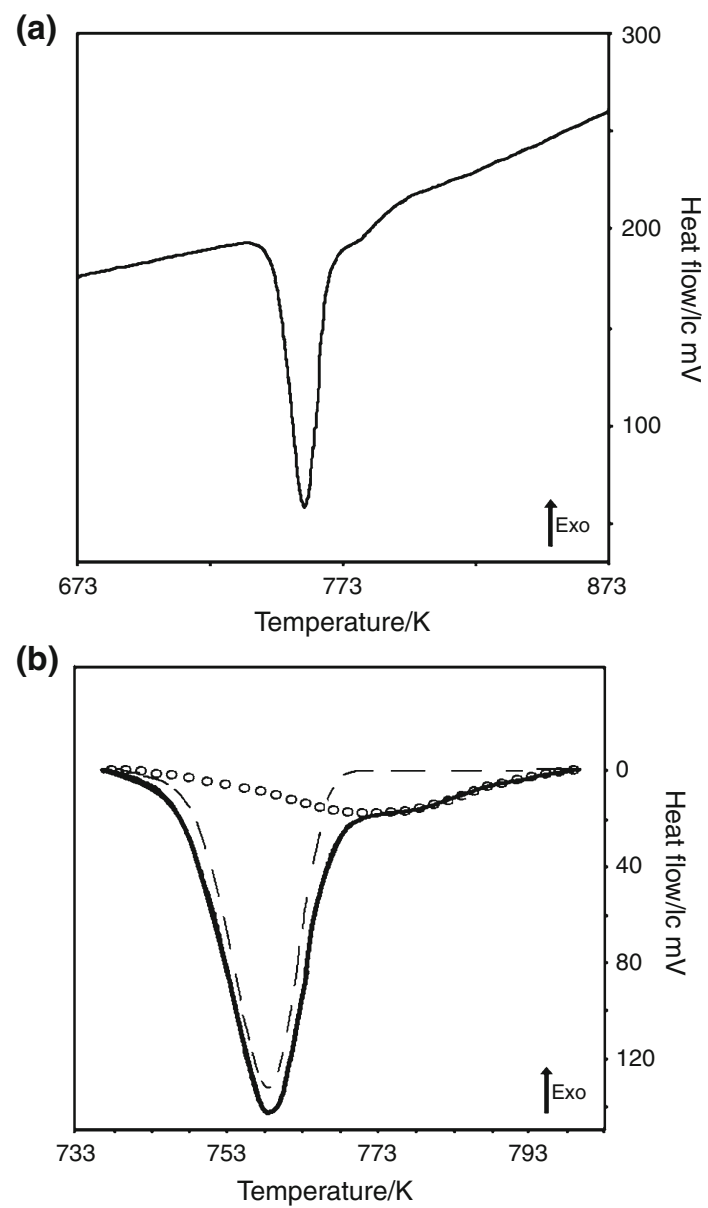

Fig. 4 DSC curve for sample with composition $x\left(\mathrm{DyCl}_{3}\right)=0.177$. a Thermal effects before peak separation, $\mathbf{b}$ thermal effects after peak separation method 
Table 1 Temperature values of thermal effects for all samples of $\mathrm{DyCl}_{3}-\mathrm{LiCl}$ binary system

\begin{tabular}{|c|c|c|c|c|}
\hline \multirow[t]{2}{*}{$x\left(\mathrm{DyCl}_{3}\right)$} & \multicolumn{4}{|l|}{ Temperature $\mathrm{K}$} \\
\hline & $\begin{array}{l}\mathrm{LiCl}-\mathrm{Li}_{3} \mathrm{DyCl}_{6} \\
\text { eutectic }(T=746 \mathrm{~K})\end{array}$ & $\begin{array}{l}\mathrm{DyCl}_{3} \text { phase transition } \\
(T=606 \mathrm{~K})\end{array}$ & $\begin{array}{l}\mathrm{Li}_{3} \mathrm{DyCl}_{6}-\mathrm{DyCl}_{3} \text { eutectic } \\
(T=672 \mathrm{~K})\end{array}$ & Liquidus \\
\hline 0 & - & - & - & 888 \\
\hline 0.050 & 745 & - & - & 858 \\
\hline 0.100 & 747 & - & - & 832 \\
\hline 0.150 & 746 & - & - & 796 \\
\hline 0.177 & 747 & - & - & 776 \\
\hline 0.200 & 747 & - & - & 763 \\
\hline 0.213 & 747 & - & - & 747 \\
\hline 0.223 & 748 & - & - & 761 \\
\hline 0.238 & 742 & - & - & 759 \\
\hline 0.251 & - & - & - & 768 \\
\hline 0.277 & - & 606 & - & 767 \\
\hline 0.301 & - & 607 & 670 & 753 \\
\hline 0.348 & - & 606 & 665 & 751 \\
\hline 0.375 & - & 609 & 675 & 730 \\
\hline 0.398 & - & 608 & 675 & 720 \\
\hline 0.424 & - & 605 & 673 & 711 \\
\hline 0.452 & - & 607 & 673 & 694 \\
\hline 0.475 & - & 606 & 674 & 674 \\
\hline 0.501 & - & 603 & 670 & 692 \\
\hline 0.552 & - & 604 & 674 & - \\
\hline 0.600 & - & 605 & 673 & 748 \\
\hline 0.648 & - & 606 & 672 & 778 \\
\hline 0.698 & - & 605 & 670 & 804 \\
\hline 0.752 & - & 606 & 672 & 826 \\
\hline 0.795 & - & 606 & 672 & 842 \\
\hline 0.848 & - & 606 & 671 & 865 \\
\hline 0.904 & - & 605 & 669 & 884 \\
\hline 0.951 & - & 605 & 666 & 901 \\
\hline 1.000 & - & 609 & - & 914 \\
\hline
\end{tabular}

All the results of DSC investigations are presented in Table 1, and the complete phase diagram is shown in Fig. 5.

The determined by us phase diagram of $\mathrm{DyCl}_{3}-\mathrm{LiCl}$ binary system is completely different from the one presented in the literature [16]. Although in both cases the existence of $\mathrm{Li}_{3} \mathrm{DyCl}_{6}$ compound was confirmed, our findings showed that it melts congruently at $768 \mathrm{~K}$, whereas according to the literature data it melts incongruently at $748 \mathrm{~K}$ and additionally undergoes a solid-solid phase transition at $743 \mathrm{~K}$. As a consequence of congruent melting of $\mathrm{Li}_{3} \mathrm{DyCl}_{6}$, two eutectics were found by us, namely $\mathrm{LiCl}-\mathrm{Li}_{3} \mathrm{DyCl}_{6}\left(\right.$ at $x=0.206\left(T_{\text {eut }}=746 \mathrm{~K}\right)$ ) and $\mathrm{Li}_{3} \mathrm{DyCl}_{6}-\mathrm{DyCl}_{3} \quad$ (at $x=0.542 \quad(T=674 \mathrm{~K})$ ). The literature data [16] show only one, $\mathrm{Li}_{3} \mathrm{DyCl}_{6}-\mathrm{DyCl}_{3}$ eutectic (at $x=0.515(T=721 \mathrm{~K})$ ). The composition of this eutectic is the only similarity to our results, but its melting temperature is significantly higher than ours (721 and $674 \mathrm{~K}$, respectively). In addition, we found a solidsolid phase transition of $\mathrm{DyCl}_{3}$ in agreement with the literature data [19], whereas this transition is absent in the literature phase diagram [16].

The $\mathrm{DyCl}_{3}-\mathrm{LiCl}$ system is characterized by the existence of $\mathrm{Li}_{3} \mathrm{DyCl}_{6}$ compound. The electrical conductivity of $\mathrm{Li}_{3} \mathrm{DyCl}_{6}$ was also measured in the liquid and solid phase. It was found to be a solid electrolyte with a high electrical conductivity at about room temperature. 
Fig. 5 Phase diagram of the $\mathrm{DyCl}_{3}-\mathrm{LiCl}$ binary system. Values in bracketsexperimental data from [16]

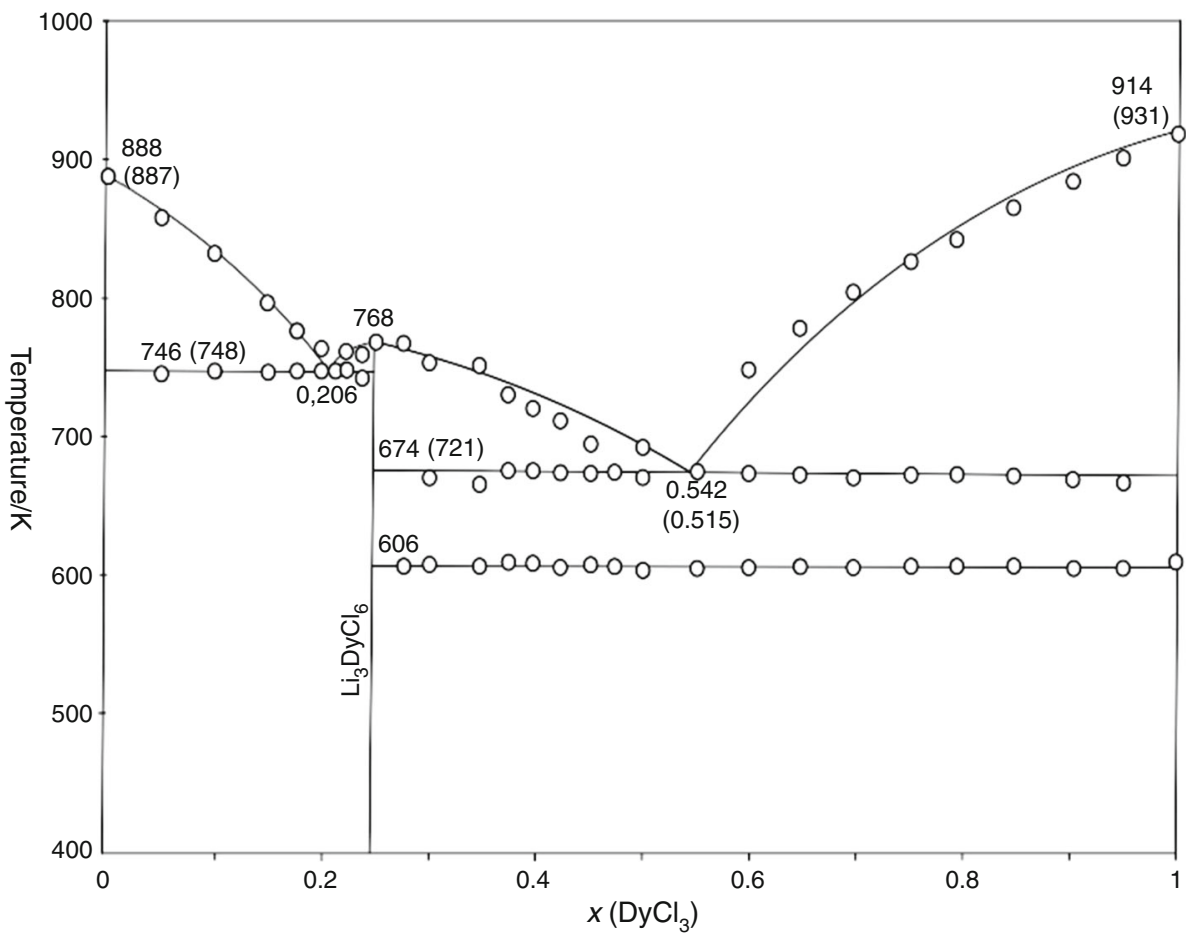

\section{Conclusions}

1. The complete $\mathrm{DyCl}_{3}-\mathrm{LiCl}$ phase diagram shows the existence of $\mathrm{Li}_{3} \mathrm{DyCl}_{6}$ compound that melts congruently at $768 \mathrm{~K}$ with enthalpy of $51.6 \mathrm{~kJ} \mathrm{~mol}^{-1}$.

2. Tammann diagram is an important outcome for the theory of phase diagram. It predicts, through application of the lever rule, the variation of the enthalpy associated with the first-order transformation as a function of concentration. Regrettably, this plot is seldom used or merely overlooked, although it provides valuable information.

3. Tammann diagrams construction allows to precisely determine the composition of eutectics existing in the system.

4. The composition and temperature of eutectics were determined as $x\left(\mathrm{DyCl}_{3}\right)=0.206 ; T_{\text {eut }}=746 \mathrm{~K}$ and $x\left(\mathrm{DyCl}_{3}\right)=0.542 ; T_{\text {eut }}=674 \mathrm{~K}$.

Acknowledgements The work was financed by a statutory activity subsidy from the Polish Ministry of Science and Higher Education for the Faculty of Chemistry of Wroclaw University of Technology.

Open Access This article is distributed under the terms of the Creative Commons Attribution 4.0 International License (http://crea tivecommons.org/licenses/by/4.0/), which permits unrestricted use, distribution, and reproduction in any medium, provided you give appropriate credit to the original author(s) and the source, provide a link to the Creative Commons license, and indicate if changes were made.

\section{References}

1. Naumov VS, Bychkov AV, Lebedev A. Advenctes in molten salts: from structural aspects to waste processing. In: Gaude-Escard M, editor. Properties of liquid-salt nuclear fuel and its reprocessing technology. Danbury: Begell House Inc; 1999. p. $432-53$.

2. Junming T, Bath NY. Quarty metal halide lamp with improved lumen maintenance. U.S. Patent Application Publication. 2008; US2008/0093993 Ai.

3. Junming T, Bath NY. Quarty metal halide lamp with improved lumen maintenance. U.S. Patent Application Publication. 2010; US 7, 786,674 B2.

4. Guest EC, Mucklejohn SA, Preston B, Rouffet JB, Zissis G., NumeLiTe: an energy effective lighting system for roadways and an industrial application of molten salts. In: Oye HA, Jagtoyen A editors, Proceedings of International Symposium on Ionic Liquids in Honour of M. Gaune-Escard, Carry le Rouet, France 2003; 26-28: pp. 37-45.

5. Seifert HJ. Ternary chlorides of the trivalent late lanthanides: phase diagrams, crystal structures and thermodynamic properties. J Therm Anal Calorim. 2006;83:479-505.

6. Gmelin L. Handbook of Inorganic Chemistry. 8th ed., vol. C5. Berlin: Springer; 1977.

7. Prosypajko VI, Alekseeva EA. Phase equilibria in binary halides. In: Bell HB, editor. New York: IFI/Plenum.

8. Korshunov BG, Drobot DV. Interaction of gadolinium and dysprosium chlorides with chlorides of sodium and potassium (in Russian). Zh Neorg Khimii. 1965;10:939-42.

9. Seifert HJ, Sandrok J, Uebach J. Thermochemical and structural investigations on the systems $\mathrm{NaCl} / \mathrm{TbCl}_{3}$ and $\mathrm{NaCl} / \mathrm{DyCl}_{3}$. Acta Chemica Scandavica. 1995;49:653-7.

10. Blachnik R, Selle D. Zur Thermochemie von AlkalichloridLanthanoid(III)-chloriden. Z Anorg Allg Chem. 1979;454:90-8. 
11. Seifert HJ. Ternary chlorides of the trivalent early lanthanides: phase diagrams, crystal structures and thermodynamic properties. J Therm Anal Calorim. 2002;67:789-826.

12. Seifert $\mathrm{HJ}$, Krämer R. Ternare chloride in den systemen $\mathrm{ACl} /$ $\mathrm{DyCl}_{3}(\mathrm{~A}=\mathrm{Cs}, \mathrm{Rb}, \mathrm{K})$. Z Anorg Allg Chem. 1994;620:1543-8.

13. Chao-Gui Zheng, Shou-Lin Huang, Si-Qiang Wang. Phase diagram of binary systems $\mathrm{ErCl}_{3}-\mathrm{MCl}_{\mathrm{n}}(\mathrm{M}=\mathrm{Li}, \mathrm{Ca}, \mathrm{Pb} ; \mathrm{n}=1$ or 2). Chem J Chin Univ. 1993;14:992-5.

14. Chao-Gui Zheng, Shou-Lin Huang, Si-Qiang Wan. Phase Diagram of Binary Systems $\mathrm{YbCl}_{3}-\mathrm{MCl}_{\mathrm{n}}(\mathrm{M}=\mathrm{Li}, \mathrm{Mg}, \mathrm{Ca}, \mathrm{Pb}$; $\mathrm{n}=1$ or 2). Acta Phys Chim Sin. 1994;10:342-7.

15. Chao-Gui Zheng, Shou-Lin Huang, Si-Qiang Wang. Phase diagram of binary system $\mathrm{HoCl}_{3}-\mathrm{MCl}_{\mathrm{n}}(\mathrm{M}=\mathrm{Li}, \mathrm{Mg}, \mathrm{Ca}, \mathrm{Pb} ; \mathrm{n}=1$ or 2). Acta Chim Sinica. 1994;52:735-9.

16. Chao-Gui Zheng, Zhong-Dong Zhao, Si-Qiang Wang. Phase diagram of binary systems $\mathrm{DyCl}_{3}-\mathrm{MCl}(\mathrm{M}=\mathrm{Li}, \mathrm{Mg}, \mathrm{Ca}, \mathrm{Pb}$; $\mathrm{n}=1$ or 2). Inst Sci Tech Inf China. 1994;18:263.
17. Gaune-Escard M, Rycerz L, Szczepaniak W, Bogacz A. Enthalpies of phase transition in the lanthanide chlorides $\mathrm{LaCl}_{3}, \mathrm{CeCl}_{3}$, $\mathrm{PrCl}_{3}, \mathrm{NdCl}_{3}, \mathrm{GdCl}_{3}, \mathrm{DyCl}_{3}, \mathrm{ErCl}_{3}$ and $\mathrm{TmCl}_{3}$. J Alloys Comp. 1994;204:193-6.

18. Rycerz L. Thermochemistry of lanthanide halides and compounds formed in lanthanide halide-alkali metal halide systems (in Polish). Scientific Papers of Institute of Inorganic Chemistry and Metallurgy of Rare Elements. Wroclaw University of Technology. 2004;35.

19. Findlay A. The phase rule and its applications. New York: Longmans, Green and Co.; 1911.

20. Guenet JM. Contributions of phase diagrams to the understanding of organized polymer-solvent systems. Thermochim Acta. 1996;284:67-83.

21. Rycerz L. Practical remarks concerning phase diagram determination on the base of DSC measurements. J Therm Anal Cal. 2013;113:231-8. 